\title{
Water kept liquid by warmth from within
}

IT has been known for over 20 years that water can collect in spots beneath the Antarctic ice sheet as it does under smaller, warmer glaciers, and that a subglacial lake exists near Vostok station in central East Antarctica. The occurrence of pools of liquid water beneath the frigid East Antarctic ice sheet, whose mean temperature in its upper parts is $-50{ }^{\circ} \mathrm{C}$ or colder and whose top surface never reaches melting point even on the warmest of summer days, is not as surprising as it might seem.

The reason is simple - the bed of the ice sheet is heated from below by the geothermal flux that characterizes the Earth everywhere, and the four-kilometre-thick blanket of ice, a good thermal insulator, isolates it from the extreme cold above. The temperature of the basal ice is raised to melting point and any excess heat (another source is the frictional heat of sliding) will go towards melting the ice.

As also discussed in the accompanying article by Ellis-Evans and WynnWilliams, Kapitsa et al. ${ }^{1}$ have brought together data collected by several techniques over the past four decades to provide a fuller description of Lake Vostok. Kapitsa's re-examination of his seismic soundings made at Vostok station in 1959-60, and new seismic measurements completed just last season, have revealed the great water depth; radio-echo sounding by Robin in the 1970s mapped the ice thickness; and up-to-the-minute analysis of ERS-1 satellite radar altimetry by Ridley provides surface elevations of such remarkable precision that they can prove, from comparisons of surface slope and ice thickness, that the ice floats on fresh water, not salt.
It is the sheer size of Lake Vostok, comparable in area to Lake Ontario and in depth perhaps even to Lake Baikal, that makes this new description so startling. How has so much water collected in one place? Where does it come from? Where does it go?

The answers to these questions are

\section{IMAGE UNAVAILABLE FOR COPYRIGHT REASONS}

White blue yonder - Vostok station (bottom), almost lost in the immensity of Antarctica.

not yet available in detail, but the general principles of subglacial water movement are easily understood. As in more familiar examples on the Earth's surface, water flow under an ice sheet is simply driven by gravity. The driving force arises from a combination of two factors: pressure ('head') differences, from the loads of different thicknesses of overlying ice, which would force water to flow even along a horizontal bed (like water from a reservoir moving through a level pipe); and bed-surface slope, down which the water tends to flow just as it does down a mountainside. Less obvious is the fact that surface slopes (head gradients) are ten times more effective at driving water than bed slopes. Consequently, in most unfrozen places under most glaciers, water flows along the bed in the general direction of the surface slope.

Ice sheets in general, however, and particularly in central East Antarctica, are characterized by minuscule surface slopes - 1 metre per kilometre is typical. It follows that bed slopes of as little as one degree will control the water flow, so the water will collect in depressions in the bed, just as it does on the surface. Also, just as on land, it will fill a depression until it reaches the level of an outlet, through which it will then flow. When the width of a lake becomes many times the overlying ice thickness, the ice floats freely, in hydrostatic equilibrium, on (or in) the water of the lake. It then becomes exceedingly flat and level, like an Antarctic ice shelf, and no longer contributes to the driving force.

Kapitsa et al. estimate a mean residence time of water in the lake of some 50,000 years; even more intriguing than that is the age of the oldest water, which depends crucially on the deep circulation within Lake Vostok. What that is no one will know before it is measured directly - and there's the rub, as Ellis-Evans and Wynn-WIIliams explain.

Charles Bentley

Charles Bentley is at the Polar Research Center, University of Wisconsin, Madison, Wisconsin 53562, USA. stantially different from that at the downstream end, $-2.46{ }^{\circ} \mathrm{C}$, because of the 500-m drop in height. This temperature differential may induce circulation within the lake, a fact of considerable biological relevance. The downward movement of ice into the melting zone will release compressed atmospheric gases, such as oxygen, trapped in the ice structure for hundreds of thousands of years. In certain permanently ice-covered lakes of southern Victoria Land, continuous exclusion of gases during ice formation at the under-ice surface, coupled with extremely low microbial consumption of these gases, results in supersaturation of both oxygen and nitrogen ${ }^{3}$. A similar exclusion process may feasibly occur at the downstream edge of the lake/ice-sheet interface in Lake Vostok, so supersaturation is a slight possibility. High oxygen tensions are known to be toxic to certain microorganisms.

Microbiological studies of the Vostok ice core have revealed a great diversity of microbes, including yeasts and actinomycetes (with antibiotic-synthesizing potential) which remain viable in ice for up to 3,000 years, and viable mycelial fungi up to 38,600 years old. A unicellular alga, Crucigenia tetrapodia, has been found $1,525 \mathrm{~m}$ down (in ice about 110,000 years old $)^{4}$ and diatom shells have been observed at 2,375 m (180,000 years old; S. S. Abyzov, personal communication). The oldest viable forms obtained to date are spore-forming bacteria at $2,395 \mathrm{~m}$ $(200,000 \text { years old })^{5}$. There is therefore a ready source of microbes seeding the lake.

Radar altimetry and radio-echo studies suggest that the lake water has little or no salts in it. The possibility does exist, however, of inorganic ions of atmospheric origin, concentrated in the ice, creating an acid lake environment. The likely dearth of nutrients does not necessarily mean that this is a sterile environment, as microbes tend in such circumstances to shrink and form microcells $(<0.1 \mu \mathrm{m}$ diameter), and can slow down their metabolism 6 . The high pressures to which the microbes will be exposed on melting of the surrounding ice will affect the viability of some microorganisms, but pressure resistance is well documented in marine microbes ${ }^{7}$.

It appears that water temperatures are just below zero, posing few problems for Antarctic microbes, and the geothermal heating that keeps the lake liquid (see the accompanying article by Bentley) could create an even warmer environment in the 